\title{
Đánh giá chất lượng bộ câu hỏi sát hạch lý thuyết lái xe mô tô Hạng A1 mới
}

\section{Quality assessment of new Class A1 motorcycle riding theory test questions}

\author{
Nguyễn Xuân Trung ${ }^{1 *}$, Dương Văn Lập ${ }^{1}$ \\ ${ }^{1}$ Trường Cao đẳng Giao thông Huế, Việt Nam \\ "Tác giả liên hệ, Email: nxtrung.gtvthue@ gmail.com
}

THÔNG TIN

DOI: 10.46223/HCMCOUJS. soci.vi.16.2.1951.2021

Ngày nhận: 21/06/2021

Ngày nhận lại: 18/08/2021

Duyệt đăng: 23/08/2021

Tù khóa:

câu hỏi điểm liệt; chất lượng; đánh giá; hạng A1; sát hạch lý thuyết

\section{Keywords:}

"fail" questions; quality; assessment; class A1; theory test

\section{TÓM TÁT}

Có thể khẳng định chất lượng đào tạo và sát hạch lý thuyết lái xe phụ thuộc vào chất lượng bộ đề. Dù có một số thay đổi so với bộ đề sát hạch cũ, nhưng qua phân tích độ khó và cách thức biên soạn, có thể nhận định rằng bộ 200 câu hỏi sát hạch lý thuyết lái xe hạng $\mathrm{A} 1$ vẫn chưa có chất lượng hơn bộ cũ và khó có thể đánh giá việc học tập lý thuyết lái xe một cách hiệu quả. Cụ thể là chỉ có $0.5 \%$ câu hỏi khó, $3.5 \%$ trung bình và $96 \%$ dễ, trong đó, có đến $43.5 \%$ số câu hỏi là hoàn toàn dễ dàng, ai dự sát hạch cũng trả lời đúng. Có $74.5 \%$ vi phạm nguyên tắc viết câu hỏi trắc nghiệm nhiều lựa chọn, từ thể thức đến nội dung. Ngoài ra, có thể khẳng định rằng câu hỏi "điểm liệt" chỉ là một cách thức gây khó, chứ không giúp nâng cao hiệu quả. Để cải thiện chất lượng đào tạo và sát hạch lái xe, sửa đổi và hoàn thiện các bộ câu hỏi sát hạch lái xe của tất cả các hạng là một việc làm cấp thiết.

\section{ABSTRACT}

It is possible to confirm that the quality of riding theory training and testing depends on the quality of the test designed. Although there are some changes compared to the old set, analysis of difficulty and compilation method shows that the set of 200 Class A1 motorcycle riding theory test items is still not better quality than the old one and is difficult to assess effective theory learning. Specifically, only $0.5 \%$ of the questions are difficult, $3.5 \%$ are average, and $96 \%$ are easy, of which $43.5 \%$ of the questions are completely easy; everyone who took the test answered correctly. There are $74.5 \%$ violated the principles of writing multiple-choice questions, from format to content. In addition, it can be affirmed that the "fail" questions are just one way that makes it difficult, not to improve test efficiency. To improve riding training and testing quality, it is imperative to modify and complete theory test items for all classes.

\section{Giới thiệu}

Sát hạch lý thuyết lái xe bằng câu hỏi trắc nghiệm nhiều lựa chọn được thực hiện từ lâu 
trên thế giới cũng như tại Việt Nam. Áp dụng từ tháng 08 năm 2020, bộ câu hỏi trắc nghiệm mới dùng để sát hạch lái xe mô tô hạng $\mathrm{A} 1$ có 200 câu so với 150 trước đó, đề cũng tăng từ 20 lên 25 câu và thời gian làm bài tăng từ 15 lên 19 phút. Ngoài ra, không còn câu hỏi có hai đáp án và mỗi đề mới có một câu "về tình huống mất an toàn giao thông nghiêm trọng", sai câu này sẽ bị truất quyền sát hạch mà không phụ thuộc vào điểm số bài làm (Bộ Giao thông vận tải, 2020), gọi nôm na là "điểm liệt." Những thay đổi này có lẽ là nhằm ngày càng nâng cao chất lượng đào tạo, sát hạch cấp giấy phép lái xe mô tô, góp phần giảm thiểu tai nạn giao thông.

Đối với trắc nghiệm khách quan, tăng số lượng câu hỏi trong ngân hàng cũng như mỗi đề thi là cần thiết. Số câu hỏi trong một đề càng nhiều thì khả năng đo lường kiến thức người học càng hiệu quả và khách quan. Nhưng sự hiệu quả này chỉ có thể đảm bảo được bằng chất lượng câu hỏi. Chẳng hạn, câu hỏi chỉ toàn ở mức độ dễ hay dễ đoán thì không cần cố gắng cũng trả lời được, câu hỏi theo kiểu mẹo mực, đánh đố thì lại chỉ làm khó chứ hoàn toàn không đánh giá được kiến thức người học. Trước đây, nhiều lỗi về chất lượng như vậy đã được chỉ ra ở bộ 150 câu hỏi sát hạch, cấp giấy phép lái xe mô tô hạng A1 và A2 (Nguyen, 2014, 2017).

Nhằm bảo đảm chất lượng, việc biên soạn và đánh giá câu hỏi trắc nghiệm luôn phải tuân theo những nguyên tắc và chỉ số nhất định. Bài viết này phân tích và đánh giá chất lượng 200 câu hỏi sát hạch lái xe mô tô hạng A1, cũng như thảo luận sự hợp lý của loại câu hỏi "điểm liệt," có lẽ là có một không hai trong sát hạch lái xe và cả trắc nghiệm khách quan trên toàn thế giới.

\section{Cơ sở lý thuyết}

Bộ 200 câu hỏi trắc nghiệm nhiều lựa chọn (Bộ Giao thông vận tải, 2020) gồm các phần nội dung và số lượng câu hỏi như trình bày ở Bảng 1 . Trong 20 câu "điểm liệt" có 18 câu thuộc phần Khái niệm và quy tắc giao thông đường bộ, 02 câu thuộc Kỹ thuật lái xe. Mỗi đề sát hạch có 25 câu, trong đó về Khái niệm và quy tắc giao thông đường bộ có 01 câu khái niệm, 06 câu quy tắc giao thông, 01 câu tốc độ, khoảng cách và có thể thêm 01 câu "điểm liệt."

\section{Bảng 1}

Cấu trúc nội dung bộ đề và đề sát hạch lái xe mô tô hạng A1

\begin{tabular}{|l|c|c|c|}
\hline \multicolumn{1}{|c|}{ Bộ đề̀ } & $\begin{array}{c}\text { Số lượng } \\
\text { trong đề sát } \\
\text { hạch }\end{array}$ \\
\hline Khái niệm và quy tắc giao thông đường bộ & Câu hỏi số & Số lượng & 8 \\
\hline Văn hóa giao thông và đạo đức người lái xe & $84-88$ & 53 & 1 \\
\hline Kỹ thuật lái xe & $89-100$ & 12 & 1 \\
\hline Hệ thống báo hiệu đường bộ & $101-165$ & 65 & 7 \\
\hline Sa hình và kỹ năng xử lý tình huống giao thông & $166-200$ & 35 & 7 \\
\hline Điểm liệt & & 20 & 1 \\
\hline
\end{tabular}

Nguồn: Tổng hợp của tác giả

Thông thường, câu hỏi trắc nghiệm nhiều lựa chọn được phân tích định lượng bằng hai chỉ số là độ khó và độ phân biệt, còn đánh giá một đề thi trắc nghiệm thì dùng độ tin cậy và độ giá trị. Tuy nhiên, trong sát hạch lý thuyết lái xe mô tô $\mathrm{A} 1$, chỉ có thể phân tích độ khó do có nhiều câu hỏi chỉ có hai lựa chọn, tức là sai về thể thức. Còn các đề sát hạch lý thuyết thì tổ hợp ngẫu nhiên từ bộ câu hỏi nên không thể xác định được cụ thể để đánh giá độ tin cậy và độ giá trị. Theo Lam (2008), độ khó của một câu hỏi được tính bằng số người trả lời đúng chia cho số 
người tham gia trả lời, giá trị càng thấp thì nghĩa là độ khó càng cao, 0.7 - 01 là câu hỏi dễ (có 70 - 100\% số người trả lời đúng), mức 0.4 - 0.6 là trung bình, từ 0.3 trở xuống là khó.

Đồng thời, để đảm bảo chất lượng đánh giá kết quả học tập, câu hỏi trắc nghiệm phải được biên soạn theo những yêu cầu nhất định. Bảng 2 trình bày các nguyên tắc viết câu hỏi trắc nghiệm dùng cho bài viết này, được tổng hợp từ những nghiên cứu của Haladyna, Downing, và Rodriguez (2002), Boland, Lester, và Williams (2010), Brame (2013) và Xu, Kauer, và Tupy (2016).

\section{Bảng 2}

Các nguyên tắc viết câu hỏi trắc nghiệm nhiều lựa chọn

\begin{tabular}{|c|l|}
\hline $\begin{array}{c}\text { Nguyên } \\
\text { tắc }\end{array}$ & \multicolumn{1}{c|}{ Nội dung } \\
\hline 1 & Phần thân câu hỏi \\
\hline 2 & Đánh giá được cấp độ tư duy hiểu, phân tích chứ không chỉ biết \\
\hline 3 & $\begin{array}{l}\text { Tránh tường chính của câu hỏi phải nằm ở phần thân } \\
\text { mạnh địn, nếu buộc phải dùng thì viết in hoa từ phủ định để nhấn }\end{array}$ \\
\hline 4 & Phần thân được trình bày rõ ràng, không chứa dữ liệu không liên quan \\
\hline 5 & Các lưa chọn \\
\hline 6 & Số phương án chọn không ít hơn 03 \\
\hline 7 & Các lựa chọn cần được trình bày rõ ràng và ngắn gọn \\
\hline 8 & Các lựa chọn phải có độ dài như nhau \\
\hline 9 & Tránh kiểu không đáp án nào, tất cả các trường hợp trên \\
\hline 10 & Các lựa chọn phải riêng biệt, không chồng chéo, không đánh lừa người dự thi \\
\hline Tránh tạo manh mối cho đáp án như các từ luôn luôn, không bao giờ, tuyệt đối, \\
\hline hoàn toàn, ..., các lựa chọn chính xác dễ nhận ra hoặc vô lý
\end{tabular}

Nguồn: Tổng hợp của tác giả

\section{Phương pháp nghiên cứu}

Kết quả sát hạch lý thuyết hạng A1 của 207 người trong hai khóa học vào tháng 01 năm 2021, tại Trường Cao đẳng Giao thông Huế, được thu thập để tính toán độ khó và phân tích kết quả. Tất cả bài sát hạch đều được thực hiện trên máy vi tính bằng phần mềm sát hạch lái xe mô tô của Tổng cục Đường bộ Việt Nam. Số người trả lời ít nhất cho một câu hỏi là 10 và nhiều nhất là 58. Đồng thời, từng câu hỏi lại được đối chiếu với 10 nguyên tắc ở Bảng 2 xem có vi phạm hay không. Các lỗi vi phạm cũng được phân tích, đánh giá. Ngoài ra, mức độ tương quan giữa độ khó và số lỗi trong mỗi câu hỏi cũng được xem xét.

\section{Kết quả nghiên cứu và thảo luận}

\subsection{Về độ khó}

Kết quả tính toán độ khó (làm tròn) được trình bày tại Bảng 3 , câu hỏi không tô mờ là câu "điểm liệt." 


\section{Bảng 3}

Độ khó của 200 câu hỏi sát hạch lái xe mô tô hạng A1

\begin{tabular}{|c|c|c|c|c|c|c|c|c|c|}
\hline $\begin{array}{c}\text { Câu } \\
\text { hỏi }\end{array}$ & $\begin{array}{c}\text { Độ̣ } \\
\text { khó }\end{array}$ & $\begin{array}{c}\text { Câu } \\
\text { hỏi }\end{array}$ & $\begin{array}{c}\text { Độ } \\
\text { khó }\end{array}$ & $\begin{array}{c}\text { Câu } \\
\text { hỏi }\end{array}$ & $\begin{array}{c}\text { Độ̣ } \\
\text { khó }\end{array}$ & $\begin{array}{c}\text { Câu } \\
\text { hôi }\end{array}$ & $\begin{array}{c}\text { Độ } \\
\text { khó }\end{array}$ & $\begin{array}{c}\text { Câu } \\
\text { hỏi }\end{array}$ & $\begin{array}{c}\text { Độ } \\
\text { khó }\end{array}$ \\
\hline 1 & 0.9 & 41 & 0.7 & 81 & 1.0 & 121 & 0.9 & 161 & 1.0 \\
\hline 2 & 1.0 & 42 & 0.9 & 82 & 0.9 & 122 & 0.9 & 162 & 1.0 \\
\hline 3 & 0.9 & 43 & 0.9 & 83 & 0.8 & 123 & 0.7 & 163 & 1.0 \\
\hline 4 & 0.9 & 44 & 0.9 & 84 & 1.0 & 124 & 0.8 & 164 & 0.8 \\
\hline 5 & 1.0 & 45 & 0.7 & 85 & 1.0 & 125 & 1.0 & 165 & 1.0 \\
\hline 6 & 0.8 & 46 & 1.0 & 86 & 1.0 & 126 & 0.5 & 166 & 0.7 \\
\hline 7 & 0.8 & 47 & 1.0 & 87 & 0.9 & 127 & 1.0 & 167 & 0.8 \\
\hline 8 & 0.8 & 48 & 0.7 & 88 & 0.8 & 128 & 1.0 & 168 & 0.9 \\
\hline 9 & 1.0 & 49 & 1.0 & 89 & 1.0 & 129 & 1.0 & 169 & 1.0 \\
\hline 10 & 0.9 & 50 & 0.9 & 90 & 1.0 & 130 & 0.7 & 170 & 1.0 \\
\hline 11 & 0.9 & 51 & 1.0 & 91 & 1.0 & 131 & 0.7 & 171 & 0.9 \\
\hline 12 & 1.0 & 52 & 0.9 & 92 & 1.0 & 132 & 0.3 & 172 & 0.8 \\
\hline 13 & 0.9 & 53 & 1.0 & 93 & 1.0 & 133 & 0.7 & 173 & 0.9 \\
\hline 14 & 0.8 & 54 & 0.9 & 94 & 0.9 & 134 & 0.6 & 174 & 0.7 \\
\hline 15 & 1.0 & 55 & 0.9 & 95 & 0.8 & 135 & 1.0 & 175 & 1.0 \\
\hline 16 & 1.0 & 56 & 1.0 & 96 & 1.0 & 136 & 0.9 & 176 & 0.9 \\
\hline 17 & 1.0 & 57 & 0.9 & 97 & 0.7 & 137 & 0.9 & 177 & 1.0 \\
\hline 18 & 1.0 & 58 & 1.0 & 98 & 1.0 & 138 & 0.9 & 178 & 0.8 \\
\hline 19 & 1.0 & 59 & 1.0 & 99 & 1.0 & 139 & 0.9 & 179 & 0.9 \\
\hline 20 & 0.8 & 60 & 1.0 & 100 & 0.9 & 140 & 0.6 & 180 & 0.8 \\
\hline 21 & 0.9 & 61 & 1.0 & 101 & 0.7 & 141 & 1.0 & 181 & 1.0 \\
\hline 22 & 0.9 & 62 & 1.0 & 102 & 0.9 & 142 & 0.7 & 182 & 1.0 \\
\hline 23 & 1.0 & 63 & 1.0 & 103 & 0.9 & 143 & 0.9 & 183 & 0.8 \\
\hline 24 & 0.6 & 64 & 1.0 & 104 & 0.8 & 144 & 0.9 & 184 & 0.9 \\
\hline 25 & 1.0 & 65 & 0.5 & 105 & 0.9 & 145 & 1.0 & 185 & 0.9 \\
\hline 26 & 0.9 & 66 & 1.0 & 106 & 1.0 & 146 & 0.9 & 186 & 0.9 \\
\hline 27 & 1.0 & 67 & 1.0 & 107 & 0.9 & 147 & 1.0 & 187 & 1.0 \\
\hline 28 & 0.8 & 68 & 1.0 & 108 & 0.9 & 148 & 0.9 & 188 & 0.9 \\
\hline 29 & 1.0 & 69 & 0.8 & 109 & 0.8 & 149 & 0.8 & 189 & 1.0 \\
\hline
\end{tabular}




\begin{tabular}{|c|c|c|c|c|c|c|c|c|c|}
\hline $\begin{array}{c}\text { Câu } \\
\text { hỏi }\end{array}$ & $\begin{array}{c}\text { Độ } \\
\text { khó }\end{array}$ & $\begin{array}{c}\text { Câu } \\
\text { hỏi }\end{array}$ & $\begin{array}{c}\text { Độ } \\
\text { khó }\end{array}$ & $\begin{array}{c}\text { Câu } \\
\text { hỏi }\end{array}$ & $\begin{array}{c}\text { Đọ } \\
\text { khó }\end{array}$ & $\begin{array}{c}\text { Câu } \\
\text { hỏi }\end{array}$ & $\begin{array}{c}\text { Độ } \\
\text { khó }\end{array}$ & $\begin{array}{c}\text { Câu } \\
\text { hỏi }\end{array}$ & $\begin{array}{c}\text { Độ } \\
\text { khó }\end{array}$ \\
\hline 30 & 0.9 & 70 & 0.8 & 110 & 0.9 & 150 & 0.6 & 190 & 0.9 \\
\hline 31 & 1.0 & 71 & 0.8 & 111 & 1.0 & 151 & 0.5 & 191 & 0.9 \\
\hline 32 & 1.0 & 72 & 0.8 & 112 & 1.0 & 152 & 0.6 & 192 & 0.9 \\
\hline 33 & 1.0 & 73 & 1.0 & 113 & 0.9 & 153 & 0.7 & 193 & 0.9 \\
\hline 34 & 1.0 & 74 & 0.8 & 114 & 1.0 & 154 & 1.0 & 194 & 0.9 \\
\hline 35 & 1.0 & 75 & 1.0 & 115 & 0.8 & 155 & 0.9 & 195 & 0.8 \\
\hline 36 & 1.0 & 76 & 1.0 & 116 & 0.9 & 156 & 0.8 & 196 & 0.8 \\
\hline 37 & 0.9 & 77 & 0.8 & 117 & 0.6 & 157 & 1.0 & 197 & 1.0 \\
\hline 38 & 0.8 & 78 & 1.0 & 118 & 0.9 & 158 & 1.0 & 198 & 1.0 \\
\hline 39 & 1.0 & 79 & 1.0 & 119 & 1.0 & 159 & 0.9 & 199 & 1.0 \\
\hline 40 & 0.9 & 80 & 0.7 & 120 & 1.0 & 160 & 0.8 & 200 & 1.0 \\
\hline
\end{tabular}

Nguồn: Tổng hợp của tác giả

Theo Bảng 3, chỉ có câu 132 thuộc phần biển báo là khó, chiếm $0.5 \%$ bộ câu hỏi. 07 câu hỏi trung bình thuộc nhiều phần khác nhau, chiếm 3.5\%, nhưng không có ở phần sa hình và kỹ năng xử lý tình huống giao thông. Còn lại $96 \%$ là những câu hỏi dễ, trong đó có 14 câu đạt độ khó $0.7,31$ câu đạt $0.8,59$ câu đạt 0.9 và 88 câu đạt 1.0 . Như vậy, có đến $43.5 \%$ số câu hỏi là hoàn toàn dễ dàng, ai dự sát hạch cũng trả lời đúng. Từ đây, có thể nhận định rằng bộ 200 câu hỏi sát hạch lý thuyết lái xe mô tô hạng $\mathrm{A} 1$ mới hoàn toàn không khó với người học, tương tự bộ 150 câu hỏi trước đây (Nguyen, 2017).

\subsection{Về nguyên tắc}

Với những câu hỏi sai nguyên tắc, hoặc là người học sẽ dễ dàng đoán được hoặc là không đo lường được kiến thức người học một cách hiệu quả và như vậy thì không đảm bảo chất lượng. Bảng 4 trình bày những lỗi sai nguyên tắc, mỗi loại lỗi được ghi bằng số tương ứng ở Bảng 2 . Có 51 câu hỏi không bị lỗi, chiếm $25.5 \%$, 101 câu bị một lỗi, chiếm $50.5 \%$, 36 câu bị hai lỗi, chiếm $18 \%$, còn lại là câu bị ba và bốn lỗi, chiếm $6 \%$. Các câu hỏi về hệ thống báo hiệu đường bộ, sa hình và kỹ năng xử lý tình huống giao thông có ít lỗi hơn các phần khác, có lẽ là do nội dung hỏi chứa hình ảnh nên rõ ràng, ít sai hơn.

Giữa độ khó và số lỗi của một câu hỏi có mức tương quan tuyến tính thuận, nghĩa là câu hỏi càng có nhiều lỗi thì giá trị độ khó càng cao, tức càng dễ trả lời. Tuy nhiên, với hệ số tương quan $\mathrm{r}=0.15$ thì đây là mức tương quan yếu.

\section{Bảng 4}

Lỗi sai nguyên tắc của 200 câu hỏi sát hạch lái xe mô tô hạng A1

\begin{tabular}{|c|c|c|c|c|c|c|c|c|c|}
\hline $\begin{array}{c}\text { Câu } \\
\text { hỏi }\end{array}$ & Lỗi & $\begin{array}{c}\text { Câu } \\
\text { hỏi }\end{array}$ & Lỗi & $\begin{array}{c}\text { Câu } \\
\text { hỏi }\end{array}$ & Lỗi & $\begin{array}{c}\text { Câu } \\
\text { hỏi }\end{array}$ & Lỗi & $\begin{array}{c}\text { Câu } \\
\text { hỏi }\end{array}$ & Lỗi \\
\hline 1 & & 41 & 4 & 81 & 1,10 & 121 & 3 & 161 & 8 \\
\hline 2 & $2,6,7,9$ & 42 & 4 & 82 & 8,10 & 122 & 4,5 & 162 & \\
\hline
\end{tabular}




\begin{tabular}{|c|c|c|c|c|c|c|c|c|c|}
\hline $\begin{array}{l}\text { Câu } \\
\text { hỏi }\end{array}$ & Lô̂i & $\begin{array}{l}\text { Câu } \\
\text { hỏi }\end{array}$ & Lô̂i & $\begin{array}{l}\text { Câu } \\
\text { hỏi }\end{array}$ & Lỗi & $\begin{array}{l}\text { Câu } \\
\text { hỏi }\end{array}$ & Lô̂i & $\begin{array}{l}\text { Câu } \\
\text { hỏi }\end{array}$ & Lô̂i \\
\hline 3 & 2,7 & 43 & 3,4 & 83 & 7 & 123 & & 163 & 5 \\
\hline 4 & 10 & 44 & 6,7 & 84 & $1,8,10$ & 124 & 3,8 & 164 & \\
\hline 5 & & 45 & 6 & 85 & 7 & 125 & & 165 & 7 \\
\hline 6 & 4,10 & 46 & 5 & 86 & 6 & 126 & 8 & 166 & \\
\hline 7 & $5,6,7,9$ & 47 & 6 & 87 & 8 & 127 & & 167 & \\
\hline 8 & 7,9 & 48 & & 88 & 8 & 128 & 8 & 168 & 5 \\
\hline 9 & 8 & 49 & & 89 & 1,10 & 129 & 8 & 169 & 5 \\
\hline 10 & 8 & 50 & 7 & 90 & $5,6,9$ & 130 & 8 & 170 & 5 \\
\hline 11 & 8 & 51 & 7 & 91 & 7 & 131 & & 171 & \\
\hline 12 & 7,10 & 52 & & 92 & $5,6,7,9$ & 132 & 8 & 172 & \\
\hline 13 & 7,9 & 53 & & 93 & 7 & 133 & & 173 & 8 \\
\hline 14 & 5,7 & 54 & 7,10 & 94 & 4 & 134 & & 174 & 8 \\
\hline 15 & 10 & 55 & & 95 & & 135 & 8 & 175 & 8 \\
\hline 16 & $1,7,10$ & 56 & & 96 & 8,10 & 136 & 8 & 176 & 8 \\
\hline 17 & 7 & 57 & 4,9 & 97 & 7,10 & 137 & & 177 & 5 \\
\hline 18 & 7 & 58 & 1 & 98 & 1,10 & 138 & & 178 & 5 \\
\hline 19 & 1,10 & 59 & 8 & 99 & & 139 & & 179 & \\
\hline 20 & & 60 & $3,7,10$ & 100 & 7 & 140 & & 180 & 5 \\
\hline 21 & 7 & 61 & 1,7 & 101 & 8 & 141 & & 181 & \\
\hline 22 & 3,10 & 62 & 6,7 & 102 & & 142 & & 182 & 7 \\
\hline 23 & & 63 & $6,7,9$ & 103 & 8 & 143 & 8 & 183 & 8 \\
\hline 24 & 3,7 & 64 & & 104 & 8 & 144 & 5 & 184 & 8 \\
\hline 25 & 7 & 65 & 3 & 105 & 8 & 145 & & 185 & 8 \\
\hline 26 & 4,7 & 66 & 7,9 & 106 & 8 & 146 & 5 & 186 & \\
\hline 27 & 1,4 & 67 & 1,6 & 107 & 8 & 147 & 8 & 187 & \\
\hline 28 & $3,4,7,10$ & 68 & 6,7 & 108 & 8 & 148 & 5 & 188 & 8 \\
\hline 29 & 4 & 69 & 3,4 & 109 & 8 & 149 & 8 & 189 & 5 \\
\hline 30 & 4,7 & 70 & 4 & 110 & 3,8 & 150 & 8 & 190 & 8 \\
\hline 31 & 4 & 71 & 4 & 111 & 8 & 151 & & 191 & \\
\hline 32 & & 72 & 4,8 & 112 & 8 & 152 & 8 & 192 & \\
\hline 33 & 7 & 73 & 8 & 113 & $3,4,8$ & 153 & & 193 & 8 \\
\hline 34 & 7 & 74 & 10 & 114 & 8 & 154 & 8 & 194 & \\
\hline
\end{tabular}




\begin{tabular}{|c|c|c|c|c|c|c|c|c|c|}
\hline $\begin{array}{c}\text { Câu } \\
\text { hỏi }\end{array}$ & Lối & $\begin{array}{c}\text { Câu } \\
\text { hỏi }\end{array}$ & Lỗi & $\begin{array}{c}\text { Câu } \\
\text { hỏi }\end{array}$ & Lỗi & $\begin{array}{c}\text { Câu } \\
\text { hỏi }\end{array}$ & Lối & $\begin{array}{c}\text { Câu } \\
\text { hỏi }\end{array}$ & Lối \\
\hline 35 & 4 & 75 & 8,10 & 115 & 3,8 & 155 & 8 & 195 & \\
\hline 36 & 8 & 76 & 1,10 & 116 & 4 & 156 & 8 & 196 & \\
\hline 37 & & 77 & 9,10 & 117 & & 157 & & 197 & \\
\hline 38 & 8 & 78 & 7 & 118 & 5 & 158 & 7 & 198 & 8 \\
\hline 39 & 4 & 79 & 1,10 & 119 & 5 & 159 & 4 & 199 & 10 \\
\hline 40 & 4 & 80 & 7 & 120 & & 160 & & 200 & \\
\hline
\end{tabular}

Nguồn: Tổng hợp của tác giả

Với một vấn đề, người học cần phải hiểu, vận dụng và thậm chí cả phân tích, đánh giá, chứ không chỉ đơn giản là biết. Có 12 câu hỏi vi phạm nguyên tắc 1 và tất cả đều có độ khó bằng 1.0. Chẳng hạn, "Câu hỏi 27: Khi điều khiển xe mô tô hai bánh, xe mô tô ba bánh, xe gắn máy, những hành vi buông cả hai tay; sử dụng xe để kéo, đầy xe khác, vật khác; sử dụng chân chống của xe quệt xuống đường khi xe đang chạy có được phép hay không?" (Bộ Giao thông vận tải, 2020, p. 10), hay "Câu hỏi 58. Người điều khiển xe mô tô hai bánh, xe gắn máy phải đội mũ bảo hiểm có cài quai đúng quy cách khi nào?” (Bộ Giao thông vận tải, 2020, p. 19) thì dù chưa học lý thuyết lái xe cũng có thể trả lời được.

Câu hỏi 2 và 3 vi phạm nguyên tắc 2 . Khi ý tưởng chính của câu hỏi không nằm phần thân sẽ làm cho người trả lời khó nắm bắt được nội dung hỏi, dẫn đến có thể trả lời sai dù có đủ kiến thức cần thiết. Ở nguyên tắc 3 , từ phủ định phải được viết in hoa để nhấn mạnh, tránh gây nhầm lẫn. Có 12 câu bị lỗi này, trong đó chỉ một câu có độ khó 1.0 và một câu 0.6 , còn lại ở mức 0.8 và 0.9 . Dĩ nhiên, nếu được biên soạn đúng, kết quả thu được sẽ tốt hơn.

Còn với nguyên tắc 4 , thân câu hỏi sử dụng từ ngữ phức tạp, trình bày dài dòng hay chứa dữ liệu không liên quan sẽ làm cho câu hỏi ít rõ ràng hơn. Lúc này câu hỏi là để kiểm tra đọc hiểu chứ không phải đánh giá xem người học có hiểu biết vấn đề hay không. Chẳng hạn, nội dung câu hỏi có xe ba bánh, xe xích lô, xe ô tô, xe máy chuyên dùng trong khi hạng A1 là mô tô hai bánh (câu 26 - 31, 35, 57, 116) hay đưa vào ba biển báo nhưng chỉ hỏi về hai biển (câu 113), thậm chí một biển (câu 159) hoặc vừa có hình biển báo lại vừa mô tả chi tiết bằng chữ về biển báo đó (câu 39 - 43). Có 24 câu hỏi bị lỗi này. Tương tự, theo nguyên tắc 6 , các lựa chọn cũng phải được biên soạn ngắn gọn, rõ ràng, thẳng vào vấn đề để có thể đo lường được kiến thức người học. Ví dụ, câu hỏi 90 có phần thân dài 25 từ với lựa chọn 01 dài 77 từ và lựa chọn 02 dài 75 từ là bị lỗi, có 12 câu hỏi như vậy.

Trong lý thuyết trắc nghiệm khách quan, câu hỏi chỉ có hai lựa chọn sẽ gồm đúng và sai, còn câu hỏi nhiều lựa chọn phải có từ ba trở lên. Tuy nhiên, vẫn có đến 19 câu vi phạm nguyên tắc 5 , nghĩa là có $9.5 \%$ số câu hỏi đã được biên soạn sai cơ bản. Dĩ nhiên, tất cả đều là câu hỏi dễ với giá trị độ khó từ 0.8 đến 1.0 .

Ở nguyên tắc 7, khi các lựa chọn có độ dài khác nhau nhiều thì cái dài nhất thường là đáp án, bởi người viết câu hỏi có xu hướng tăng độ dài của câu trả lời để đảm bảo sự đầy đủ, trung thực. Có 36 câu hỏi vi phạm điều này và trong đó có 24 câu đúng ở lựa chọn dài nhất, chiếm gần $66.7 \%$. Cả 36 câu hỏi đều là loại dễ với giá trị độ khó từ 0.8 đến 1.0.

Trong câu hỏi có ba phương án chọn, mà có "tất cả các ý trên" hoặc "không có ý nào đúng," chỉ cần tìm ra được một lựa chọn không đúng thì đáp án chính là cái còn lại. Tức là, có thể trả lời được chính xác câu hỏi mà không cần phải biết tất cả các lựa chọn. Ở câu có bốn lựa 
chọn cũng tương tự như vậy. Có 56 câu hỏi sai ở nguyên tắc này, nhiều nhất trong các lỗi, chiếm $28 \%$ bộ câu hỏi.

Câu hỏi 92 chỉ có hai lựa chọn như sau: "1- Quan sát cẩn thận các chướng ngại vật và báo hiệu bằng còi, đèn; giảm tốc độ tới mức cần thiết, về số thấp và thực hiện quay vòng với tốc độ phù hợp với bán kính cong của đường vòng. 2- Quan sát cẩn thận các chướng ngại vật và báo hiệu bằng còi, đèn; tăng tốc để nhanh chóng qua đường vòng và giảm tốc độ sau khi qua đường vòng" (Bộ Giao thông vận tải, 2020, p. 29). Đây là một câu hỏi có các lựa chọn chồng chéo nhau, gây nhầm lẫn và thậm chí đánh lừa người trả lời. Có 10 câu hỏi vi phạm nguyên tắc 9 như vậy trong bộ đề và 05 trong số đó cũng vi phạm nguyên tắc 6 , thiếu rõ ràng và ngắn gọn. Dĩ nhiên, những câu hỏi này cần phải viết lại để đảm bảo khả năng đo lường, đánh giá kiến thức của người học.

Cuối cùng, có 23 câu hỏi vi phạm nguyên tắc 10, trong đó gồm 13 câu có đáp án dễ nhận ra, 07 câu có từ tạo manh mối cho đáp án (cơ quan có thẩm quyền, bị nghiêm cấm, đường ưu tiên) và 03 câu có một lựa chọn là vô lý. Tương tự như câu hỏi chỉ ở cấp độ tư duy biết, những câu hỏi có lựa chọn tạo manh mối cho đáp án như thế này rất dễ dàng trả lời đúng.

Từ những phân tích trên, có thể nhận định rằng bộ 200 câu hỏi dùng cho sát hạch lái xe ô tô hạng A1 mới không được biên soạn theo các nguyên tắc khoa học, thậm chí là theo lý thuyết trắc nghiệm khách quan. Mặt khác, trong một nghiên cứu hạn chế về tài liệu tham khảo, các lỗi $1,4,5,6,8,10$ đã từng được chỉ ra ở bộ 150 câu hỏi dùng cho sát hạch, cấp giấy phép lái xe mô tô hạng $A 1$ và $A 2$ (Nguyen, 2014). Dù vậy, bộ câu hỏi này đã được sử dụng từ tháng 03 năm 2013 đến tháng 08 năm 2020 mà không có sửa đổi, hoàn thiện nào đáng kể. Có câu hỏi bị lỗi vẫn được sử dụng gần như nguyên vẹn trong bộ 200 câu hỏi như "16. Người điều khiển phương tiện giao thông đường bộ mà trong cơ thể có chất ma túy có bị nghiêm cấm hay không?" (Bộ Giao thông vận tải, 2020, p. 7). Như vậy, bộ câu hỏi sau chỉ là sự nối dài của bộ câu hỏi trước về số lượng mà không có sự thay đổi về chất lượng, trừ việc sửa lại các câu hỏi có hai đáp án. Điều này càng cho thấy, cả hai bộ câu hỏi đều đã không được biên soạn đúng cách, đảm bảo yêu cầu đo lường năng lực người học.

\subsection{Về câu hỏi "điểm liệt"}

Theo tác giả Lam (2008), trắc nghiệm là một phép đo lường giáo dục, đề trắc nghiệm dùng để đánh giá một năng lực nào đó của người học. Việc biên soạn câu hỏi và thiết kế các đề thi trắc nghiệm phải tuân theo những yêu cầu, nguyên tắc nhất định, nhưng hoàn toàn không có dạng câu "điểm liệt." Do chưa có mục tiêu nào về đào tạo cấp giấy phép lái xe mô tô hạng A1 được công bố nên không thể biết câu "điểm liệt" dùng để đo nội dung gì. Nhưng có thể nhận định rằng, tất cả những câu hỏi trong đề, dù được chế tác ở cấp độ tư duy nào cũng đều bị vô hiệu hóa bởi câu hỏi “điểm liệt" và do đó đây khó có thể coi là một cách đo lường.

Mặt khác, tình huống là "sự diễn biến của tình hình, về mặt cần phải đối phó" (TratuSOHA, n.d.), hỏi về một tình huống là để đo lường khả năng phân tích, suy xét. Câu hỏi tình huống mô tả một kịch bản và người trả lời phải xác định được cách giải quyết thích hợp. Loại câu hỏi này thường không thể trả lời được theo suy luận logic hay từ ngữ. Với 18 câu hỏi về khái niệm và quy tắc giao thông đường bộ, 02 về kỹ thuật lái xe, tất cả các câu "điểm liệt" đều không phải tình huống mà chỉ là nhắc lại kiến thức như các câu hỏi bình thường khác, thậm chí còn dễ trả lời hơn như ví dụ ở Bảng 5.

\section{Bảng 5}

So sánh câu hỏi “điểm liệt" và câu hỏi thường 


\begin{tabular}{|c|c|}
\hline Câu hỏi "điểm liệt" & Câu hỏi thường \\
\hline $\begin{array}{l}\text { "Câu hỏi 15: Cuộc đua xe chi được thưc } \\
\text { hiện khi nào? } \\
\text { 1- Diễn ra trên đường phố không có người } \\
\text { qua lại } \\
\text { 2- Được người dân ủng hộ } \\
\text { 3- Được cơ quan có thẩm quyền cấp phép" }\end{array}$ & $\begin{array}{l}\text { “Câu hỏi 83: Khi gặp xe buýt đang dìng đón, } \\
\text { trả khách, người điểu khiển xe mô tô phải xủ lý } \\
\text { nhu thế nào duới đây để đảm bảo an toàn giao } \\
\text { thông? } \\
\text { 1- Tăng tốc độ để nhanh chóng vượt qua bến } \\
\text { đỗ } \\
\text { 2- Giảm tốc độ đến mức an toàn có thể và quan } \\
\text { sát người qua đường và từ từ vượt qua xe buýt } \\
\text { 3- Yêu cầu phải dừng lại phía sau xe buýt chờ } \\
\text { xe rời bến mới đi tiếp" }\end{array}$ \\
\hline
\end{tabular}

Nguồn: Bộ Giao thông vận tải $(2020$, pp. 7, 26)

Vì vậy, đây còn là những câu hỏi chỉ để tăng thêm rủi ro vô ích, hoàn toàn không giúp người học nâng cao kiến thức hay đảm bảo an toàn hơn khi lái xe.

\section{Kết luận và gợi ý}

Tại nước ta, xe mô tô hạng $\mathrm{A} 1$ đang là phương tiện giao thông đường bộ chủ yếu, hàng năm có khoảng một triệu người được cấp giấy phép lái xe hạng này (Thy Nhung, 2020). Chất lượng ngân hàng câu hỏi sát hạch lý thuyết là cơ sở quan trọng để bảo đảm chất lượng đào tạo, sát hạch lái xe, từ đó đảm bảo an toàn giao thông đường bộ. Nhưng kết quả phân tích lại cho thấy bộ 200 câu hỏi sát hạch lái xe mô tô hạng A1 mới là dễ dàng với người học, vi phạm các nguyên tắc biên soạn câu hỏi trắc nghiệm. Do đó, có thể nhận định là không đảm bảo chất lượng. Đặc biệt, kiểu câu hỏi “điểm liệt" có lẽ là có một không hai trên thế giới, không chỉ với sát hạch lái xe nói riêng mà cả trắc nghiệm khách quan nói chung. Điều này đòi hỏi phải nhanh chóng có sự sửa đổi, hoàn thiện toàn bộ câu hỏi, chứ không phải từng câu riêng lẻ.

Nếu những lỗi gây nhầm lẫn cho người học ở các nguyên tắc 2, 3, 4, 6, 9 được khắc phục thì bộ câu hỏi sẽ trở nên dễ dàng hơn nữa đối với người học. Do vậy, sau khi có giấy phép lái xe có thể vẫn không đủ kiến thức để đảm bảo an toàn cho mình và người khác khi tham gia giao thông. Tuy nhiên, vì không có mục tiêu đào tạo lái xe nào được công bố, nên khó có thể đối chiếu để khẳng định.

Những vấn đề của bộ 200 câu hỏi mới lại vẫn chủ yếu là của bộ 150 câu hỏi cũ, vốn được sử dụng trong gần 08 năm và hầu như không sửa đổi, từ độ khó cho đến các nguyên tắc biên soạn. Điều này đặt ra những câu hỏi về năng lực cũng như trách nhiệm của các cơ quan quản lý nhà nước trong đào tạo, sát hạch lái xe nói chung và hạng $\mathrm{A} 1$ nói riêng. Bởi bộ 200 câu hỏi sát hạch hạng $\mathrm{A} 1$ nằm hoàn toàn trong bộ 600 câu hỏi sát hạch lái xe ô tô và có một số trong các bộ câu hỏi sát hạch lái xe hạng $\mathrm{A} 2, \mathrm{~A} 3$ và $\mathrm{A} 4$, trừ những câu hỏi "điểm liệt" có thể được lựa chọn khác nhau.

\section{Tài liệu tham khảo}

Boland, J. R., Lester, A. N., \& Williams, E. (2010). Writing multiple-choice questions. Academic Psychiatry, 34(4), 310-316.

Bộ Giao thông vận tải. (2020). Questions and answers about the Law on Road Traffic - Use for testing Class Al license. Hanoi, Vietnam: NXB Giao thông Vận Tải.

Brame, C. (2013). Writing good multiple choice test questions. Retrieved June, 19, 2021, from https://cft.vanderbilt.edu/guides-sub-pages/writing-good-multiple-choice-test-questions/ 
Haladyna, M. T., Downing, M. S., \& Rodriguez, C. M. (2002). A review of multiple-choice item-writing guidelines for classroom assessment. Applied Measurement in Education, 15(3), 309-334.

Lam, T. Q. (2008). Objective tests and application. Hanoi, Vietnam: NXB Khoa học và Kỹ thuật.

Nguyen, T. X. (2014). Some problems about multiple choices questions for riding and driving tests. Tạp chí Giáo dục và Xã hội, 37(98), 46-48.

Nguyen, T. X. (2017). Are A1 level motorcycle driving theory tests easy or hard? Tap chi Khoa họ và Công nghệ, Đại học Đà Nã̃ng, 8(117), 23-25.

Thy Nhung (2020). Nearly 600,000 car driving licenses issued in 2020. Retrieved June, 19, 2021, from Báo Pháp luật Thành phố Hồ Chí Minh website: https://plo.vn/do-thi/giaothong/gan-600000-bang-lai-xe-o-to-duoc-cap-trong-nam-2020-957082.html

Xu, X., Kauer, S., \& Tupy, S. (2016). Multiple-choice questions: Tips for optimizing assessment in-seat and online. Scholarship of Teaching and Learning in Psychology, 2(2), 147-158.

TratuSOHA. (n.d.). Tình huống [Situation]. Retrieved June, 19, 2021, from http://tratu.soha.vn/dict/vn_vn/Tình_huống 